\title{
Phototransformation of Amlodipine in Aqueous Solution: Toxicity of the Drug and Its Photoproduct on Aquatic Organisms
}

\author{
Marina DellaGreca, ${ }^{1}$ Maria Rosaria lesce, ${ }^{1}$ Marina Isidori, ${ }^{2}$ Sara Montanaro, ${ }^{1}$ \\ Lucio Previtera, ${ }^{1}$ and Maria Rubino ${ }^{1}$ \\ ${ }^{1}$ UDR Napoli 4 (Consorzio INCA), Dipartimento di Chimica Organica e Biochimica, Università degli Studi di Napoli Federico II, \\ Complesso Universitario Monte Sant'Angelo, Via Cintia 4, 80126 Napoli, Italy \\ ${ }^{2}$ Dipartimento di Scienze della Vita, II Università di Napoli, Via Vivaldi 43, 81100 Caserta, Italy
}

Received 11 May 2007; Revised 26 July 2007; Accepted 20 September 2007

Recommended by M. Bolte

The phototransformation of amlodipine in water was investigated under various conditions. A quantum yield $\Phi_{\mathrm{S}} 2.2 \times 10^{-4}$ and a half-life time $t_{1 / 2} 0.419$ days were calculated when the drug in water $\left(10^{-4} \mathrm{M}\right)$ was exposed to sunlight. The only photoproduct found was its pyridine derivative. Formation of this product was explained on the basis of a radical cation intermediate. The acute and chronic toxicity of the drug and its photoproduct were evaluated on different organisms of the freshwater chain (Brachionus calyciflorus, Thamnocephalus platyurus, Daphnia magna, Ceriodaphnia dubia). The photoproduct exhibited a stronger toxic potential than the parent drug on the long time for C. dubia.

Copyright (c) 2007 Marina DellaGreca et al. This is an open access article distributed under the Creative Commons Attribution License, which permits unrestricted use, distribution, and reproduction in any medium, provided the original work is properly cited.

\section{INTRODUCTION}

There is a growing literature relating to observation of human pharmaceuticals in the environment [1]. Drugs and drug metabolites are a new class of organic micropollutants which have been found in low concentrations in wastewater, ground and surface water [2-4]. In the recent years the importance of nonbiological alteration in the breakdown of drugs has been widely observed and has stimulated a large number of researches concerning degradation mechanisms, kinetics, isolation, and toxicity of degradation products. The last aspect is of particular interest since the metabolites may be even more toxic than the parent molecule. A regulation on the environmental effects of new pharmaceuticals is operative from 1995 in the USA [5]. The European Scientific Committee on toxicity, ecotoxicity and the environment (CSTEE) has proposed in 2001 a draft on the environmental risk assessment of medicinal products, and the need to take into account not only the drugs but also their transformation products is recommended [6]. In this context we have studied the abiotic transformation of some anti-inflammatory drugs in the aquatic environment and we have found that some byproducts are more harmful than the parent compounds [7].
In the present study we have examined the photochemical behavior of amlodipine (1) besylate [3-ethyl 5-methyl-2-(2-aminoethoxy)methyl-4-(2-chlorophenyl)-6-methyl1,4-dihydropyridine-3,5-dicarboxylate benzenesulfonate] (see Scheme 1) under different conditions to mimic the environmental abiotic transformations. Amlodipine belongs to a class of drugs called calcium channel blockers [8]. Its besylate salt is a white crystalline powder slightly soluble in water and sparingly soluble in ethanol, commercialized as Norvasc. It is among the world wide more prescript pharmaceuticals. The drug exhibits a long wavelength UV band with a maximum at $366 \mathrm{~nm}(\log \varepsilon$ 3.78); its photolability is known and causes difficulties during manufacturing and in analytical determinations [9]. Therefore, amlodipine has been exposed to solar and UV light in aqueous solution, at different $\mathrm{pHs}$ and in the presence of humic acid or nitrate. The photoproduct formed has been identified and the acute and chronic toxicity of the parent compound and its derivative on different organisms of the freshwater chain, rotifers (Brachionus calyciflorus) and crustaceans (Daphnia magna Straus, Thamnocephalus platyurus, Ceriodaphnia dubia), have been evaluated. 


\section{MATERIALS AND METHODS}

\subsection{Chemicals}

Amlodipine $\mathrm{C}_{6} \mathrm{H}_{6} \mathrm{O}_{3} \mathrm{~S}$ (amlodipine besylate, Kemprotec Limited), analytical standard grade $(90 \%), \mathrm{KNO}_{3}$, humic acid were supplied by Aldrich and used without further purification. Amlodipine $\mathbf{1}$ was obtained by dissolving the salt in ethyl acetate and removing the besylate anion with $\mathrm{NaOH}$ $10 \%$.

\subsection{Unreported spectroscopic data of amlodipine $\mathrm{C}_{6} \mathrm{H}_{6} \mathrm{O}_{3} \mathrm{~S}$}

UV $\left(\mathrm{H}_{2} \mathrm{O}\right) \lambda_{\max } \mathrm{nm}: 366$ ( $\log \varepsilon$ 3.78), 239 ( $\left.\log \varepsilon 4.17\right)$. IR $\left(\mathrm{CHCI}_{3}\right) \nu_{\max } 3410,3018,2952,1689,1609,1483 \mathrm{~cm}^{-1} .{ }^{1} \mathrm{H}$ $\operatorname{NMR}\left(499.6 \mathrm{MHz}, \mathrm{CDCI}_{3}\right) \delta \mathrm{ppm}: 7.85(\mathrm{~d}, J=6.8 \mathrm{~Hz}, 2 \mathrm{H})$ and $7.40(\mathrm{~m}, 3 \mathrm{H})$ besylate; $7.27\left(\mathrm{dd}, J=7.6,1.7,1 \mathrm{H}, \mathrm{H}-3^{\prime}\right)$; $7.18\left(\mathrm{dd}, J=8.1,1.7 \mathrm{~Hz}, 1 \mathrm{H}, \mathrm{H}-6^{\prime}\right) ; 7.06(\mathrm{dt}, J=8.1,1.7 \mathrm{~Hz}$, $\left.1 \mathrm{H}, \mathrm{H}-5^{\prime}\right) ; 7.00\left(\mathrm{dt}, J=7.6,1.7 \mathrm{~Hz}, 1 \mathrm{H}, \mathrm{H}-4^{\prime}\right) 5.40(\mathrm{~s}$, $1 \mathrm{H}, \mathrm{H}-4) ; 4.68$ and $4.56(2 \mathrm{~d}, J=14.6 \mathrm{~Hz}, 2 \mathrm{H}, \mathrm{H}-7) ; 4.01$ (m, $\left.2 \mathrm{H}, \mathrm{CH}_{3} \mathrm{CH}_{2}\right) ; 3.65$ (m, 2H, H-8); 3.56 (s, $3 \mathrm{H}, \mathrm{OCH}_{3}$ ); 3.08 (br s, $2 \mathrm{H}, \mathrm{H}-9) ; 2.11$ (s, 3H, $\left.\mathrm{CH}_{3}\right) ; 1.17$ (t, $J=7.2 \mathrm{~Hz}$, $\left.3 \mathrm{H}, \mathrm{CH}_{3} \mathrm{CH}_{2}\right) .{ }^{13} \mathrm{C}$ NMR $\left(125.6 \mathrm{MHz}, \mathrm{CDCI}_{3}\right) \delta \mathrm{ppm:} 144.0$; $134.2(\times 2) ; 128.8 ; 128.5(\times 2)$ besylate; $168.3\left(\mathrm{CO}_{2} \mathrm{CH}_{3}\right)$; $167.5\left(\mathrm{CO}_{2} \mathrm{C}_{2} \mathrm{H}_{5}\right) ; 147.9(\mathrm{C}-6) ; 147.6(\mathrm{C}-2) ; 142.3\left(\mathrm{C}-1^{\prime}\right)$; $134.8\left(\mathrm{C}-2^{\prime}\right) ; 131.0\left(\mathrm{C}-3^{\prime}\right) ; 130.6\left(\mathrm{C}-6^{\prime}\right) ; 128.8\left(\mathrm{C}-4^{\prime}\right) ; 127.7$ $\left(\mathrm{C}-5^{\prime}\right) ; 70.0(\mathrm{C}-7) ; 68.6(\mathrm{C}-8) ; 61.7\left(\mathrm{CH}_{3} \mathrm{CH}_{2}\right) ; 52.6\left(\mathrm{CH}_{3} \mathrm{O}\right)$; 41.6 (C-9); $38.8(\mathrm{C}-4) ; 20.5\left(\mathrm{CH}_{3}\right) ; 16.2\left(\mathrm{CH}_{3} \mathrm{CH}_{2}\right)$.

\subsection{Analytical methods and equipments}

UV/Vis spectra were recorded in methanol on a Perkin-Elmer Lambda 7 spectrophotometer. IR spectra were recorded on a Jasco FT/IR-430 instrument. NMR spectra were recorded on a Varian Inova-500 instrument operating at 499.6 and $125.6 \mathrm{MHz}$ for ${ }^{1} \mathrm{H}$ and ${ }^{13} \mathrm{C}$, respectively, and referenced with deuterated solvents $\left(\mathrm{CDCI}_{3}\right)$. Low-resolution electron ionization mass spectra were obtained operating at $70 \mathrm{eV}$ on a GC-MS (QP-5050A Shimadzu).

Analytical and preparative TLC were made on Kieselgel $60 \mathrm{~F}_{254}$ plates with $0.2 \mathrm{~mm}$ and 0.5 or $1 \mathrm{~mm}$ layer thickness, respectively (Merck).

A photoreactor (Helios Italquartz) equipped with a $500 \mathrm{~W}$ high-pressure mercury lamp (through a Pyrex glass filter, $\lambda>300 \mathrm{~nm}$ ) was used for UV irradiation.

\subsubsection{Sunlight irradiation of amlodipine besylate and amlodipine (1)}

The commercial product $(15 \mathrm{mg})$ was dissolved in milliQ water $(25 \mathrm{~mL})$ in Pyrex tube, saturated with oxygen and exposed to sunlight at r.t. during summer in Naples. After 1 week the solution was evaporated and analyzed by ${ }^{1} \mathrm{H}-\mathrm{NMR}$ and TLC. The residue $(12 \mathrm{mg})$ was chromatographed on preparative TLC [eluent: ethyl acetate/ethanol/water (2/1/4)] to give unreacted drug (in trace) and a product $(11 \mathrm{mg})$ that was subjected to extraction with $\mathrm{NaOH} 10 \%$ and ethyl acetate. The organic layer after removal of solvent gave compound 2 (see Scheme 1) which was identified by spectral data.
A similar experiment was carried out starting from amlodipine (1) which gave the same result as starting from amlodipine besylate.

\subsubsection{Photoproduct 2 spectroscopic data}

$\mathrm{UV}\left(\mathrm{CH}_{3} \mathrm{OH}\right) \lambda_{\max } \mathrm{nm}: 242(\log \varepsilon 4.24), 270(\log \varepsilon$ 4.05). IR $\left(\mathrm{CHCI}_{3}\right) v_{\max } 2952,1728 \mathrm{~cm}^{-1}$. EIMS: $406\left(\mathrm{M}^{+\bullet}\right) ; 362(\mathrm{M}-$ $\left.\mathrm{CH}_{2} \mathrm{CH}_{2} \mathrm{NH}_{2}\right)^{+}$; $347\left(\mathrm{M}-\mathrm{CO}_{2} \mathrm{CH}_{3}\right)^{+} .{ }^{1} \mathrm{H}$ NMR $(499.6 \mathrm{MHz}$, $\left.\mathrm{CDCl}_{3}\right) \delta: 7.40\left(\mathrm{~d}, J=7.0 \mathrm{~Hz}, 1 \mathrm{H}, \mathrm{H}-3^{\prime}\right) ; 7.28\left(\mathrm{~m}, 2 \mathrm{H}, \mathrm{H}-4^{\prime}\right.$ and $\left.\mathrm{H}-5^{\prime}\right) ; 7.18$ (d, $\left.J=7.0 \mathrm{~Hz}, 1 \mathrm{H}, \mathrm{H}-6^{\prime}\right) ; 4.80$ and $4.82(2 \mathrm{~d}$, $J=11.7 \mathrm{~Hz}, 2 \mathrm{H}, \mathrm{H}-7) ; 4.00\left(\mathrm{q}, J=7.5 \mathrm{~Hz}, 2 \mathrm{H}, \mathrm{CH}_{3} \mathrm{CH}_{2}\right)$; $3.58(\mathrm{~m}, 2 \mathrm{H}, \mathrm{H}-8) ; 3.53\left(\mathrm{~s}, 3 \mathrm{H}, \mathrm{CH}_{3} \mathrm{O}\right) ; 2.92(\mathrm{~m}, 2 \mathrm{H}$, $\mathrm{H}-9) ; 2.65\left(\mathrm{~s}, 3 \mathrm{H}, \mathrm{CH}_{3}\right) ; 0.92\left(\mathrm{t}, J=7.5 \mathrm{~Hz}, 3 \mathrm{H}, \mathrm{CH}_{3} \mathrm{CH}_{2}\right)$. ${ }^{13} \mathrm{C}$ NMR $\left(125.6 \mathrm{MHz}, \mathrm{CDCl}_{3}\right) \delta: 167.2\left(\mathrm{CO}_{2} \mathrm{CH}_{3}\right) ; 166.6$ $\left(\mathrm{CO}_{2} \mathrm{C}_{2} \mathrm{H}_{5}\right) ; 156.2$ (C-6); 156.1 (C-2); 145.0 (C-4); 134.8 $\left(\mathrm{C}-1^{\prime}\right) ; 132.5\left(\mathrm{C}-2^{\prime}\right) ; 130.2\left(\mathrm{C}-6^{\prime}\right) ; 129.8\left(\mathrm{C}-3^{\prime}\right) ; 129.1\left(\mathrm{C}-5^{\prime}\right)$; 128.3 (C-5); 126.3 (C-3); 126.1 (C-4'); 72.9 (C-7); 72.0 (C-8); $61.4\left(\mathrm{CH}_{3} \mathrm{CH}_{2}\right) ; 52.2\left(\mathrm{CH}_{3} \mathrm{O}\right) ; 41.0(\mathrm{C}-9) ; 23.2\left(\mathrm{CH}_{3}\right)$; $13.4\left(\mathrm{CH}_{3} \mathrm{CH}_{2}\right)$.

\subsection{Sunlight irradiation of amlodipine besylate under different conditions}

Four $10^{-4} \mathrm{M}$ solutions of commercial product were exposed to sunlight in water, in the presence of nitrate $(10 \mathrm{ppm})$, at $\mathrm{pH} 4.0$ and 9.0 by adjusting the $\mathrm{pH}$ with $\mathrm{HCl} 2 \mathrm{M}$ and $\mathrm{KOH}$ $2 \mathrm{M}$, respectively. UV spectrum of each solution, at different times, was recorded and the related optical density graphically reported (Figure 1). After completion of each reaction the solution was evaporated and analyzed by NMR and TLC showing the presence of only compound 2 besylate.

A similar experiment was carried out by adding humic acid ( $5 \mathrm{ppm}$ ) to a $10^{-4}$ solution of amlodipine besylate. After 20 hours of irradiation NMR and TLC analyses of the residue after water evaporation showed that the drug was completely converted to compound 2 besylate.

\subsubsection{Determination of quantum yield under environmental conditions}

Sunlight irradiation experiments were performed during summer in Naples $\left(40^{\circ} \mathrm{N}-14^{\circ} \mathrm{E}\right)$ in Pyrex tubes $(25 \mathrm{ml})$ at r.t. Actinometry was carried by using solution of PNAP $(2.0 \times$ $\left.10^{-5} \mathrm{M}\right)$ and different concentration of pyridine [10]. The pyridine concentrations were chosen to adjust the quantum yield of the PNAP $\left(\Phi_{\text {ATT }}=0.0169\right.$ [pyridine] $)$ to modify the rate of PNAP to match the rate of consumption of the tested drug [11].

The decay of the concentration of both the investigated substrate $(S)$ and PNAP follows pseudo-first-order kinetics. Therefore, if the results collected during a single photolytic run are reported as $\ln S_{t} / S_{0}$ versus $\ln [\mathrm{PNAP}]_{t} /[\mathrm{PNAP}]_{0}$, a linear relationship is obtained:

$$
\ln \frac{S_{t}}{S_{0}}=\frac{k_{S}}{k_{\mathrm{ATT}}} \ln \frac{[\mathrm{PNAP}]_{t}}{[\mathrm{PNAP}]_{0}} .
$$

For a fixed latitude and season, the measured rate constants, $k_{S}$ and $k_{\mathrm{ATT}}$, depend on the reaction quantum yields 
<smiles>CCOC(=O)C1=C(C)NC(COCCN)=C(C(=O)CC)C1c1ccccc1Cl</smiles>

Amlodipine $1 \cdot \mathrm{C}_{6} \mathrm{H}_{6} \mathrm{O}_{3} \mathrm{~S}$<smiles>CCOC(=O)c1c(COCCN)nc(C)c(C(C)=O)c1-c1ccccc1Cl</smiles>

Compound $2 \cdot \mathrm{C}_{6} \mathrm{H}_{6} \mathrm{O}_{3} \mathrm{~S}$

Scheme 1: Structures of drug and its photoproduct.

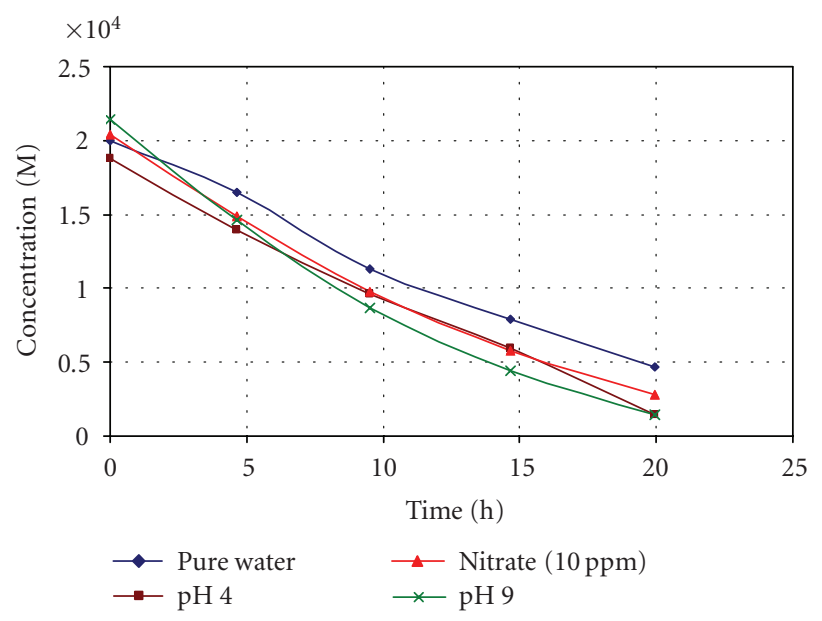

FIGURE 1: Disappearance of amlodipine-besylate in $10^{-4} \mathrm{M}$ aqueous solution by sunlight exposure under different conditions.

( $\Phi_{S}$ and $\Phi_{\text {ATT }}$ ) and molar absorptivities of the substrates and of PNAP:

$$
\begin{aligned}
k_{S} & =\phi_{S} \sum_{\lambda}\left(\varepsilon_{\lambda} L_{\lambda}\right)_{S}, \\
k_{\mathrm{ATT}} & =\phi_{\mathrm{ATT}} \sum_{\lambda}\left(\varepsilon_{\lambda} L_{\lambda}\right)_{\mathrm{ATT}},
\end{aligned}
$$

where $\varepsilon_{\lambda}\left(1 \mathrm{~mol}^{-1} \mathrm{~cm}^{-1}\right)$ are molar absorption coefficients at wavelength $\lambda$, and $L_{\lambda}$ is the average daily irradiance over wavelength interval centred at wavelength $\lambda\left(10^{-3} \mathrm{E} \mathrm{cm}^{-2}\right.$ day $\left.^{-1}\right)$. The product $\varepsilon_{\lambda} L_{\lambda}$ has the units of day ${ }^{-1}$. Values of $L_{\lambda}$ and $\sum\left(\varepsilon_{\lambda} L_{\lambda}\right)_{\text {ATT }}$ are reported in the literature for different seasons and decadic latitudes [12, 13]. Rearranging (2) will result in

$$
\frac{\phi_{S} \sum_{\lambda}\left(\varepsilon_{\lambda} L_{\lambda}\right)_{S}}{k_{S}}=\frac{\phi_{\mathrm{ATT}} \sum_{\lambda}\left(\varepsilon_{\lambda} L_{\lambda}\right)_{\mathrm{ATT}}}{k_{\mathrm{ATT}}} .
$$

The quantum yields for the reaction with different chemicals in bidistilled water under sunlight irradiation can be derived by rearranging (3):

$$
\phi_{S}=\frac{k_{S}}{k_{\mathrm{ATT}}} \frac{\phi_{\mathrm{ATT}} \sum_{\lambda}\left(\varepsilon_{\lambda} L_{\lambda}\right)_{\mathrm{ATT}}}{\sum_{\lambda}\left(\varepsilon_{\lambda} L_{\lambda}\right)_{S}} .
$$

TABLE 1: Quantum yield of photolysis reaction of amlodipine.

\begin{tabular}{lcc}
\hline Conditions & $\Phi$ & $t_{1 / 2}$ (day) \\
\hline $\mathrm{H}_{2} \mathrm{O}$ (air) & $2.2 \times 10^{-4}$ & 0.42 \\
$\mathrm{H}_{2} \mathrm{O}$ (Ar) & $1.7 \times 10^{-4}$ & 0.56 \\
$\mathrm{CH}_{3} \mathrm{CN}$ (air) & $6.1 \times 10^{-5}$ & 2.3 \\
$\mathrm{CH}_{3} \mathrm{CN}$ (Ar) & $6.7 \times 10^{-5}$ & 2.1 \\
\hline
\end{tabular}

In the present work, half-life times of the pharmaceutical for summer was calculated using the following equation:

$$
t_{1 / 2}=\frac{\ln 2}{k_{S}}=\frac{\ln 2}{\phi_{S} \sum_{\lambda}\left(\varepsilon_{\lambda} L_{\lambda}\right)_{S}} .
$$

From linear plots of $\ln S_{t} / S_{0}$ versus $\ln [\mathrm{PNAP}]_{t} /[\mathrm{PNAP}]_{0}$, the ratios $k_{S} / k_{\text {ATT }}$ were derived for amlodipine besylate, and used to evaluate its quantum yield (Table 1 ):

$$
\Phi_{S}=2.2 \times 10^{-4} \quad \text { with } t_{1 / 2}=0.419 \text { days. }
$$

\subsubsection{Determination of quantum yields under different conditions}

Amlodipine solutions in water saturated with argon, in $\mathrm{CH}_{3} \mathrm{CN}$ and in $\mathrm{CH}_{3} \mathrm{CN}$ saturated with argon, were exposed to sunlight, and examined as above for the determination of the quantum yields up to $15-20 \%$ conversion of the drug. The results are reported in Table 1 . The residue of each solution after evaporation of the solvent was also analyzed by ${ }^{1} \mathrm{H}$ NMR.

\subsection{Toxicity testing}

Acute and chronic toxicity was determined on primary consumers of the aquatic chain: rotifers (Brachionus calyciflorus) and crustaceans (Daphnia magna Straus, Thamnocephalus platyurus, Ceriodaphnia dubia). All organisms were provided in cryptobiotic stages by MicroBioTests Inc., Nazareth, Belgium, except $C$. dubia that was obtained from our laboratory cultures. Acute bioassays were conducted under static conditions, measuring dissolved oxygen and $\mathrm{pH}$ in each sample both at the start and at the end of testing. While testing toxicity, reference tests were performed. Amlodipine and 


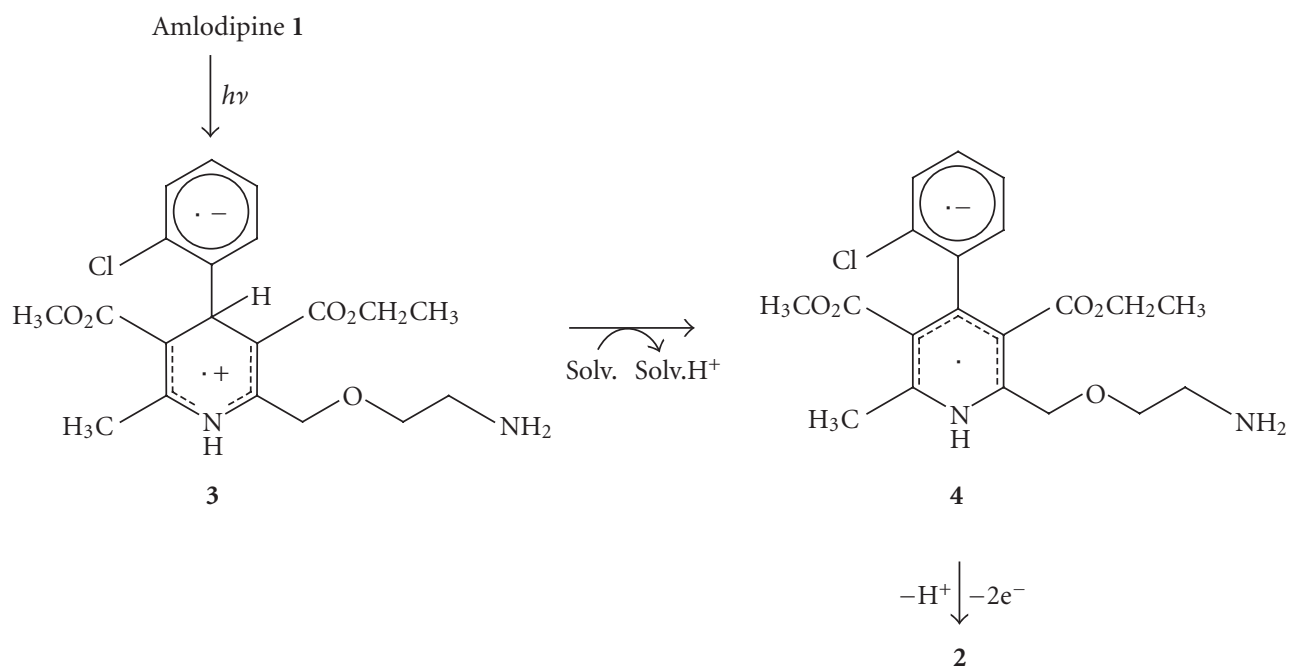

Scheme 2: Mechanistic hypothesis for compound 2.

its derivative were initially dissolved in dimethylsulphoxide (DMSO) and then diluted in double-deionized water (stock solutions). The percentage of DMSO was kept constant at $0.01 \%(\mathrm{v} / \mathrm{v})$, that is a non-effect dose as estimated in preliminary tests. Compounds concentrations used in the definitive tests were based on results from range-finding tests to determine the tolerance range of the test organisms. The test solutions were prepared by mixing the appropriate volumes of the stock solutions to be tested and the medium provided by the different guidelines [14-16] and the manufactures procedure for T. platyurus.

Neonates of the rotifer $B$. calyciflorus were exposed to the test sample in five concentrations and six replicates of five organisms for 24 hours at $25^{\circ} \mathrm{C}$, in the dark. At the end of the test the killed rotifers were scored and the concentration found to determine $50 \%$ mortality in rotifers in 24 hours was indicated as LC50 [14].

Larvae of the crustacean T. platyurus (anostraca) were exposed to five concentrations of the drug and its photoproduct in three replicates of ten organisms per concentration for 24 hours at $25^{\circ} \mathrm{C}$, in the dark. The test parameter considered was mortality and the concentration found to kill 50\% crustaceans in 24 hours was indicated as LC50.

Juveniles of the crustacean D. magna were exposed to five concentrations of the samples in four replicates for each concentration at $20^{\circ} \mathrm{C}$ in the dark for 24 and 48 hours to determine the concentration able to achieve $50 \%$ immobilization (EC50 at 24 hours and EC50 at 48 hours) of the exposed organisms [15].

The chronic test on females of C. dubia was run over a period of 7 days according to the standard ISO procedure [16] and performed on $<24$ hours old daphnids. One female, in ten replicates, was exposed to seven concentrations (twofold dilutions) at $25^{\circ} \mathrm{C}$ with a $16: 8$ hours light: dark cycle (500 lux). Every day the neonates released by the organisms exposed were counted prior to renewals and feed and then discharged. By comparing the number of offspring at the end of the test in the sample batch and the control, it was possible to calculate the concentration which gave rise to a $50 \%$ population growth inhibition, indicated as EC50.

The compounds were tested three times (three independent assays) and the data reported are the average of these bioassays. For acute toxicity tests, the LC50 and EC50 with $95 \%$ confidence intervals were calculated by concentration/response regression using probit or trimmed SpearmanKarber method. For the chronic test with C. dubia, the value of the concentration that gave the $50 \%$ population growth inhibition with 95\% confidence intervals was calculated using the maximum likelihood-logit method.

\section{RESULTS AND DISCUSSION}

\subsection{Irradiation data}

In a first stage the drug was kept in the dark in order to evaluate its transformation in absence of light. The experiments in water and at different $\mathrm{pHs}$ showed that it was recovered unchanged even after 30 days.

In a first experiment a solution of amlodipine in water $\left(10^{-4} \mathrm{M}\right)$ was exposed to sunlight exhibiting a quantum yield $\Phi_{S} 2.2 \times 10^{-4}$ and $t_{1 / 2} 0.42$ days. The photochemical behavior of the drug was then studied in water using $10^{-4} \mathrm{M}$ solutions under different conditions (by exposing to direct solar light or to UV lamp (Pyrex filter), in air-equilibrated or argon-flushed solutions, at different $\mathrm{pHs}$, in the presence of humic acid or nitrate). Figure 1 reports the decrease of the drug exposed to solar light in water, at pH 4.0, at pH 9.0 and in the presence of nitrate (ten equivalents) by measuring the optical density at $366 \mathrm{~nm}$. As shown, the half-life time is ca. 10 hours with a slight acceleration of phototransformation under basic conditions and in the presence of nitrate. The effect of humic acid could not be kinetically analyzed, since it presents absorption in the same region $(350-370 \mathrm{~nm})$ as the drug. However, ${ }^{1} \mathrm{H}$ NMR analysis of a solution of the drug 
and humic acid (40 ppm) exposed to sunlight showed that the drug was almost completely transformed after 20 hours. Quantum yield values are comparable if calculated in aerated and oxygen-free solutions, while they appear to depend on the solvent nature (Table $1, \Phi_{\text {water }} 2.2 \times 10^{-4}$ to $\Phi_{\mathrm{MeCN}}$ $\left.6.1 \times 10^{-5}\right)$. The ${ }^{1} \mathrm{H}$ NMR analysis of all the irradiation mixtures evidenced the presence of one product which was isolated by chromatography and identified as the corresponding pyridine derivative 2 on the basis of spectral data. Compound 2 showed a molecular peak at $m / z 406\left[\mathrm{M}_{\text {drug }}-2 \mathrm{H}\right]^{+}$ in the EI-MS spectrum and the absence of the proton and carbon signals of the $\mathrm{CH}$ group in the ${ }^{1} \mathrm{H}$ and ${ }^{13} \mathrm{C}$ NMR spectra due to the aromatization of heterocyclic moiety. Consequently, no long wavelength band due to the dihydropyridine moiety was present in the UV spectrum.

\subsection{Mechanism}

Aromatization of the dihydropiridine moiety is the only photoreaction observed under all conditions used. Oxygen has no significant effect on the oxidation rate [17] since compound 2 is also formed in argon-flushed solutions. Differently, conversion of amlodipine in $\mathrm{CH}_{3} \mathrm{CN}$ was slower than in water indicating that the solvent can play a role. According to Albini's investigation on 4-aryl-1,4-dihydropyridines analogues [18], a possible mechanism is shown in Scheme 2. The zwitterionic biradical 3 should be formed by an intramolecular photo-induced electron transfer. Proton transfer should be then promoted by the suitable basic solvent (more efficiently with water than with less basic $\mathrm{CH}_{3} \mathrm{CN}$ ) and this reaction followed by stepwise oxidation of the resulting anion 4 to the final product.

The complete availability of the nitrogen electron pair at $\mathrm{pH}$ 9.0, the oxidant properties of nitrate [19], and the sensitizing capability of humic acid [20] account for the faster transformation in these conditions.

\subsection{Toxicity data}

The results of acute and chronic toxicity for amlodipine and its photoderivative are presented in Table 2 and expressed as median effective concentrations (LC50 or EC50) towards the different aquatic organisms utilized. L(E)C50 values were based on nominal concentrations and not on measurements of actual test solutions. Data showed that the acute toxic potential of parent compound for D. magna at 24 and 48 hours was in the order of dozens of $\mathrm{mg} / \mathrm{L}$ while amlodipine photoproduct did not determine an immobilization at the maximum concentration tested $(50 \mathrm{mg} / \mathrm{L})$. Amlodipine was more toxic for the inferior organisms of the freshwater chain, in fact, rotifers (B. calyciflorus) and anostraca crustacea (T. platyurus) showed LC50 values of 0.57 and 2.56, respectively. Anyhow, the photoproduct evidenced significantly lower toxicities. Nevertheless, the acute effect concentrations were higher than those generally found for drugs in the aquatic environment. The chronic effects of the drug and its photoproduct were investigated on $C$. dubia reproduction in 7-days studies. The results indicated a strong decrease in the EC50 value, one or two orders of magnitude lower than
TABLE 2: Acute and chronic L(E)C50 in mg/L for amlodipine and its photoderivative with the respective confidence limits (95\%) for different organisms of the freshwater chain (NT = not toxic).

\begin{tabular}{|c|c|c|}
\hline \multirow{2}{*}{$\mathrm{L}(\mathrm{E}) \mathrm{C} 50$} & Amlodipine (1) & Photoproduct (2) \\
\hline & \multicolumn{2}{|c|}{ Acute effect } \\
\hline B. calyciflorus 24 hours & 0.57 & 38.69 \\
\hline (rotifers) & $(0.50-0.64)$ & $(33.54-46.95)$ \\
\hline T. platyurus 24 hours & 2.56 & 38.78 \\
\hline (anostraca, crustacea) & $(2.21-2.86)$ & $(33.04-45.51)$ \\
\hline D. magna 24 hours & 26.40 & NT at 50 \\
\hline (cladocera, crustacea) & $(24.25-28.74)$ & N1 at 50 \\
\hline \multirow{3}{*}{ D. magna 48 hours } & 17.90 & NT at 50 \\
\hline & $(16.88-18.99)$ & \\
\hline & \multicolumn{2}{|c|}{ Chronic effect } \\
\hline C. dubia 7 days & 0.29 & 0.041 \\
\hline (cladocera, crustacea) & $(0.11-0.39)$ & $(0.012-0.096)$ \\
\hline
\end{tabular}

the acute ones except rotifers that, as already reported, however evidenced a strong acute effect for amlodipine. The behavior of the photoproduct was peculiar, in fact its toxic activity was particularly expressed in the long term with an EC50 value of $0.041 \mathrm{mg} / \mathrm{L}$.

\section{CONCLUSIONS}

Amlodipine undergoes an easy light-induced aromatization to pyridine derivative 2 , the conversion being particularly favoured by the aqueous media. Generally less toxic than the parent drug, the photoproduct exhibited higher long-term toxicity towards C. dubia. This finding is of particular concern for the environment where drugs may be phototransformed in more toxic compounds whose occurrence data are, moreover, unknown and may cause serious adverse impact on the organisms exposed. The possibility for continual but undetectable or unnoticed effects on aquatic organisms is particularly worrisome because effects could accumulate so slowly that major change goes undetected until cumulative level of these effects finally cascades to irreversible change-change that would otherwise be attributed to natural adaptation or ecological succession [21]. Nowadays ecotoxicological studies are limited and particularly based acute toxicity tests on single aquatic organisms $[2,21]$.

\section{ACKNOWLEDGMENT}

NMR experiments have been performed at Centro Interdipartimentale di Metodologie Chimico-Fisiche of University Federico II of Naples on the $500 \mathrm{MHz}$ Varian spectrometer of Naples Laboratory of Consortium INCA.

\section{REFERENCES}

[1] K. Kümmerer, "Pharmaceuticals in the environment-scope of the book and introduction," in Pharmaceuticals in the Environment: Sources, Fate, Effects and Risks, K. Kümmerer, Ed., pp. 3-11, Springer, Berlin, Germany, 2004. 
[2] B. Halling-Sørensen, S. Nors Nielsen, P. F. Lanzky, F. Ingerslev, H. C. Holten-Lützhøft, and S. E. Jørgensen, "Occurrence, fate and effects of pharmaceutical substances in the environment-a review," Chemosphere, vol. 36, no. 2, pp. 357-393, 1998.

[3] P. Spengler, W. Körner, and J. W. Metzger, "Substances with estrogenic activity in effluents of sewage treatment plants in southwestern Germany. 1. Chemical analysis," Environmental Toxicology and Chemistry, vol. 20, no. 10, pp. 2133-2141, 2001.

[4] T. Heberer, "Occurrence, fate, and removal of pharmaceutical residues in the aquatic environment: a review of recent research data," Toxicology Letters, vol. 131, no. 1-2, pp. 5-17, 2002.

[5] FDA, Streamlining food and drug administration-environmental assessments. FDA Backgrounder BG ${ }_{95-9}$, March 1995.

[6] CSTEE (Scientific Committee on ToxicityEcotoxicity the Environment), CPMPpaperRAssessHumPharm12062001, 2001.

[7] M. DellaGreca, M. Brigante, M. Isidori, et al., "Phototransformation and ecotoxicity of the drug Naproxen-Na," Environmental Chemistry Letters, vol. 1, no. 4, pp. 237-241, 2003.

[8] J. E. Arrowsmith, S. F. Campbell, P. E. Cross, et al., "Long-acting dihydropyridine calcium antagonists. 1. 2alkoxymethyl derivatives incorporating basic substituents," Journal of Medicinal Chemistry, vol. 29, no. 9, pp. 1696-1702, 1986.

[9] G. Ragno, A. Garofalo, and C. Vetuschi, "Photodegradation monitoring of amlodipine by derivative spectrophotometry," Journal of Pharmaceutical and Biomedical Analysis, vol. 27, no. 1-2, pp. 19-24, 2002.

[10] D. Dulin and T. Mill, "Development and evaluation of sunlight actinometers," Environmental Science and Technology, vol. 16, no. 11, pp. 815-820, 1982.

[11] OECD (Organization for Economic Cooperation Development), Environmental Health and Safety Publication, 2000.

[12] R. G. Zepp and D. M. Cline, "Rates of direct photolysis in aquatic environment," Environmental Science and Technology, vol. 11, no. 4, pp. 359-366, 1977.

[13] EPA (United States Environmental Protection Agency), "Fate, transport and transformation test guidelines. Direct photolysis rate in water by sunlight," OPPTS 835.2210, Washington, DC, USA, 1996.

[14] ASTM (American Society for Testing Materials), "Standard guide for acute toxicity with the rotifer Brachionus," E 144091, Philadelphia, PA, USA, 1991.

[15] ISO (International Organization for Standardization), "Water Quality-Determination of the inhibition of the mobility of Daphnia magna Straus (Cladocera, Crustacea)-Acute toxicity test," ISO/6341. Geneva, Switzerland, 1996.

[16] ISO (International Organization for Standardization), "Water quality-Determination of chronic toxicity to Ceriodaphnia dubia in 7 days-Population growth inhibition test," ISO/CD 20665. Geneva, Switzerland, 2001.

[17] J. Shibuya, M. Nabeshima, H. Nagano, and K. Maeda, "Photochemical reaction of 2,4,4,6-tetrasubstituted 1,4dihydropyridines in deaerated media: photocolouration and photorearrangement accompanying dehydrogenation," Journal of the Chemical Society-Perkin Transactions II, no. 8, pp. 1607-1612, 1988.

[18] E. Fasani, M. Fagnoni, D. Dondi, and A. Albini, "Intramolecular electron transfer in the photochemistry of some nitrophenyldihydropyridines," Journal of Organic Chemistry, vol. 71, no. 5, pp. 2037-2045, 2006.
[19] R. G. Zepp, J. Holgné, and H. Bader, "Nitrate-induced photooxidation of trace organic chemicals in water," Environmental Science and Technology, vol. 21, no. 5, pp. 443-450, 1987.

[20] R. G. Zepp, P. F. Schlotzhauer, and R. M. Sink, "Photosensitized transformations involving electronic energy transfer in natural waters: role of humic substances," Environmental Science and Technology, vol. 19, no. 1, pp. 74-81, 1985.

[21] C. G. Daughton and T. A. Ternes, "Pharmaceuticals and personal care products in the environment: agents of subtle change?" Environmental Health Perspectives, vol. 107, supplement 6, pp. 907-938, 1999. 


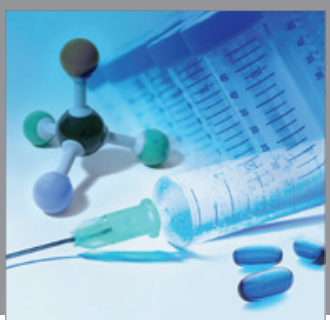

International Journal of

Medicinal Chemistry

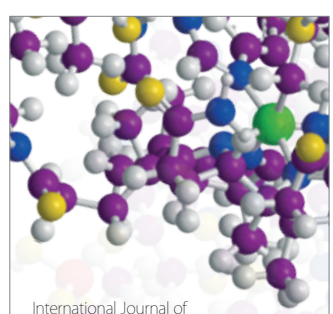

Carbohydrate Chemistry

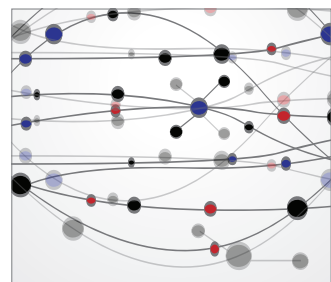

The Scientific World Journal
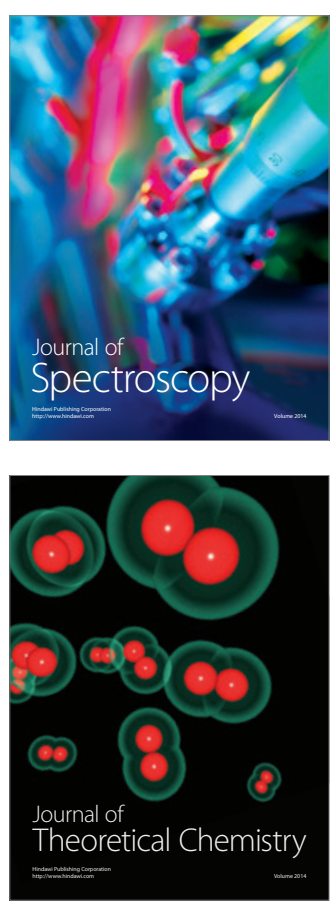
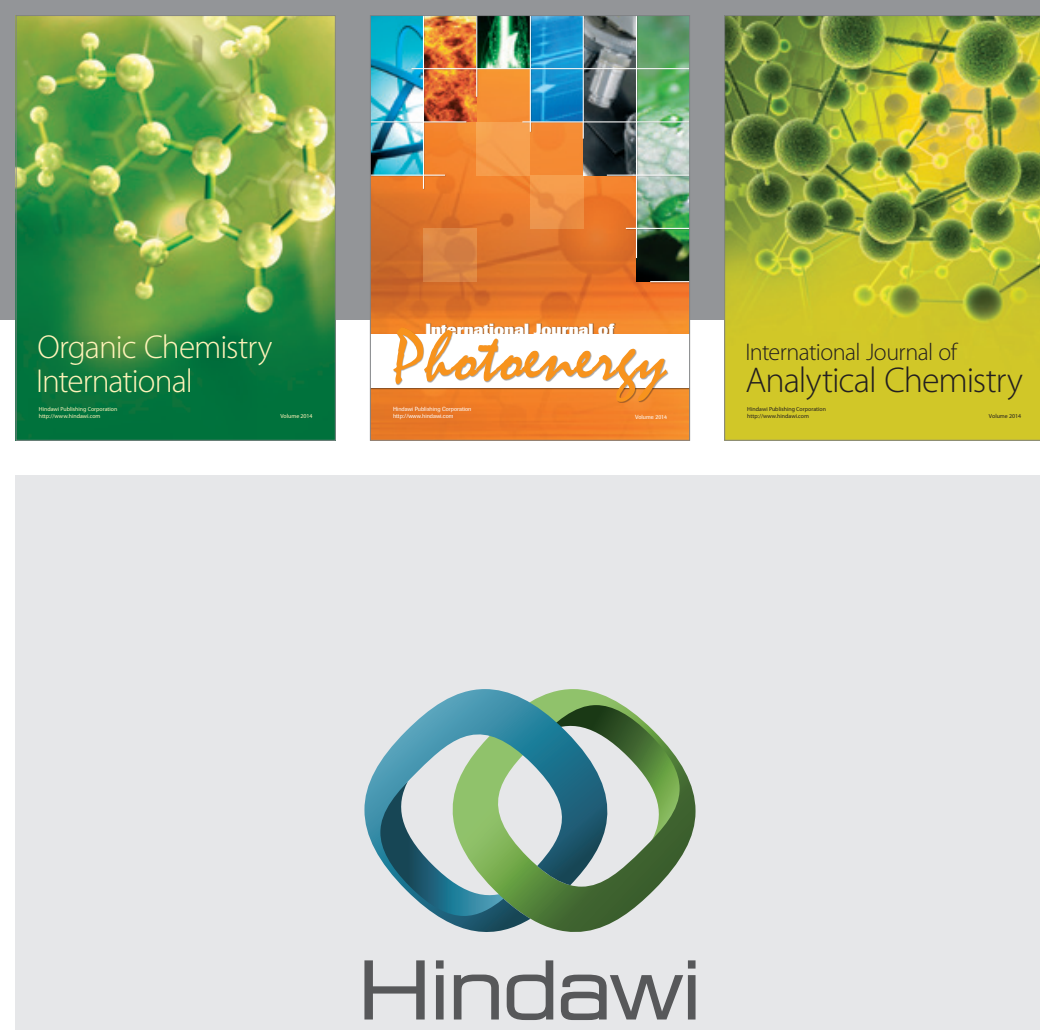

Submit your manuscripts at

http://www.hindawi.com
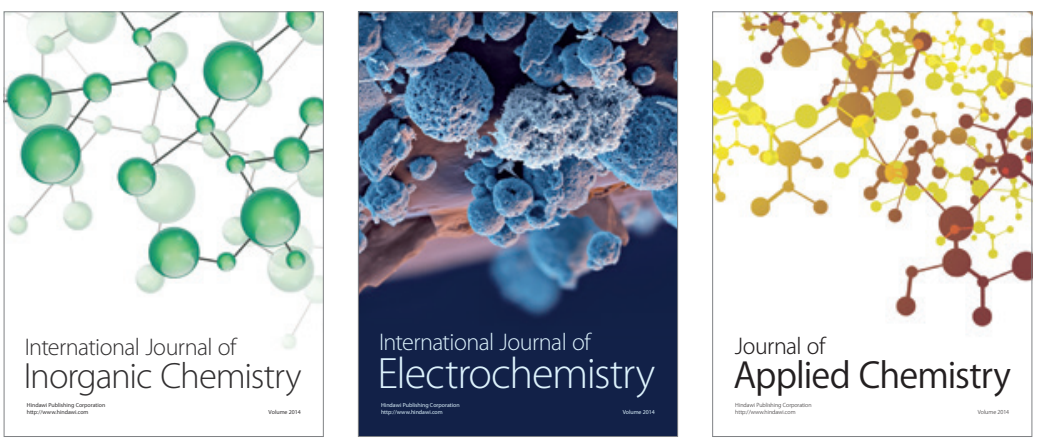

Journal of

Applied Chemistry
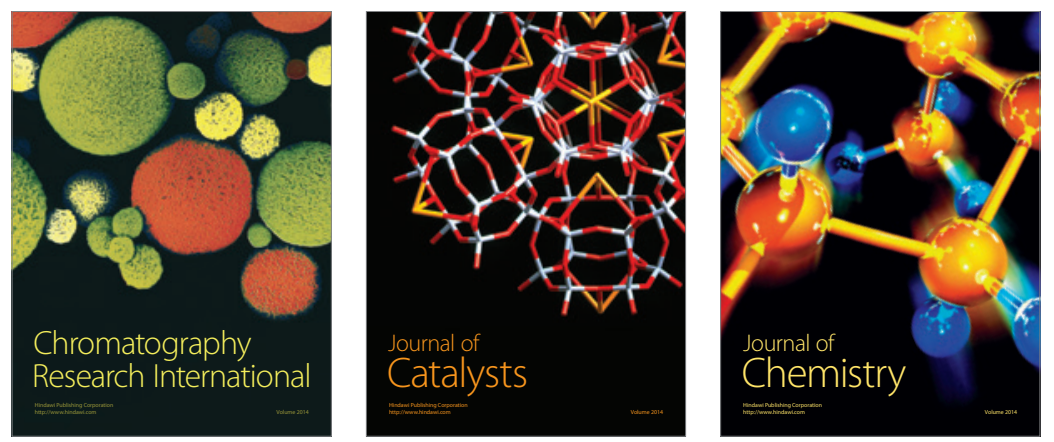
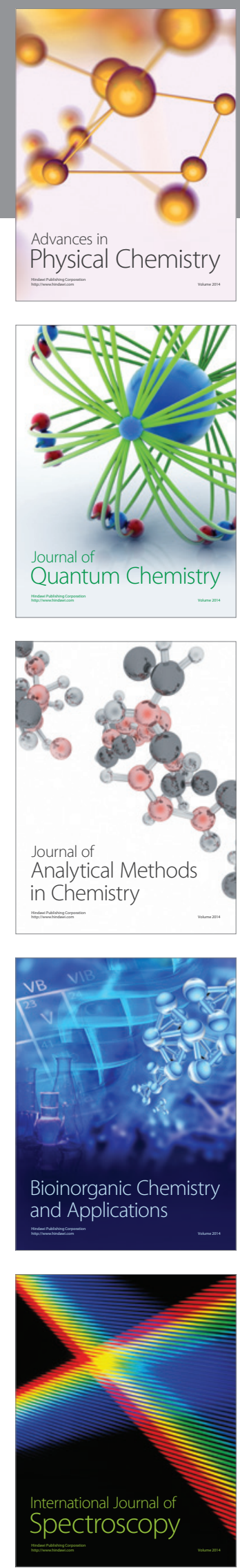